\title{
Cabaret Mineiro: o cinema sertanejo de Carlos Prates Cabaret Mineiro: Carlos Prates' backland cinema
}

Branco Di Fátima ${ }^{1}$ 
Resumo: Este ensaio visita a obra do cineasta mineiro Carlos Alberto Prates Correia, focando especialmente no seu filme mais emblemático, Cabaret Mineiro (1980). O argumento apresentado é que Prates construiu, ao longo de sua carreira, um cinema sertanejo, caracterizado pela confluência de elementos folclóricos, musicais e estéticos próprios do modo de vida do norte de Minas Gerais. Prates também parece aprofundar a adaptação da literatura para o cinema por meio de um diálogo denso com o universo mítico de João Guimarães Rosa.

Palavras-chave: Carlos Prates; cinema sertanejo; Cabaret Mineiro; literatura.

Abstract: This article visits the cinematographic work of Carlos Alberto Prates Correia, especially focusing on his most emblematic film, Cabaret Mineiro (1980). The argument presented is that Carlos Prates built, throughout his career, a backland cinema, characterized by the confluence of folkloric, musical and aesthetic elements typical of the way of life in the north of Minas Gerais. Prates also seems to deepen the adaptation of literature for cinema through a dense dialogue with the mythical universe of João Guimarães Rosa. Keywords: Carlos Prates; backland cinema; Cabaret Mineiro; literature. 


\section{A estética ardente do sertanejo}

Céu azul e nuvens carregadas. Uma estrada de terra batida. Poeira. A caatinga e um desfile de catopês. A bandeira do divino tremula em movimentos circulares de fé e de devoção dos caboclos. Avana (Tânia Alves), trajada de dançarina espanhola, encara uma plateia imaginária. A sua pose buliçosa, com espartilho para aumentar o volume dos seios, vestido vermelho e roupa íntima de renda, contracena com o pôr do sol. A aridez provocante, que dialoga com o cotidiano e a sensualidade do sertão, compõe o cartaz de Cabaret Mineiro (1980), de Carlos Alberto Prates Correia.

Esse longa-metragem, que levou cerca de 170 mil espectadores às salas de cinema, é uma comédia musical ou, como o próprio Carlos Prates (SERRA; IKEDA, 2013 , p. 42) prefere chamar, "estílico-musical”. Baseado no conto Sorôco, sua mãe, sua filha, do livro Primeiras Estórias, de João Guimarães Rosa, o filme é um recorte imagético e sonoro dos costumes, das crenças, da religiosidade, da cultura e dos modos de vida de uma subcultura: a sertaneja.

Os 68 minutos de Cabaret Mineiro se passam no interior de Minas Gerais. Paixão (Nelson Dantas), um elegante aventureiro, se apaixona por Salinas (Tamara Taxman), em uma viagem de trem a Montes Claros. Depois de uma noite de amor na cabine-leito, a mulher desaparece misteriosamente, sem deixar pistas do seu paradeiro. Assim, o aventureiro começa uma saga em busca de Salinas. Na jornada, Paixão se envolve em orgias, festejos populares e jogos de pôquer ao lado de Thomas Caps (Helber Rangel), um estadunidense importado para o sertão mineiro que interferirá no desfecho da história. Mesmo com todas as andanças - e os personagens prateanos são “eternos viajantes” (IKEDA, 2013, p. 26) -, o aventureiro não consegue esquecer Salinas, um símbolo da mulher ideal que insiste em aparecer nos seus sonhos. Curiosamente, Salinas é uma cidade do norte de Minas Gerais, casa de algumas das mais tradicionais cachaças nacionais, como Havana - nome de outra personagem importante da trama.

Cabaret Mineiro é um filme debochado, profano e sagrado, com enredo simples. As sequências alternam-se entre os pontos de vista do narrador e do personagem principal. Rodado em $35 \mathrm{~mm}$, a nudez é exposta e encoberta por superexposição em algumas cenas. Ao melhor estilo da Nouvelle Vague, é “um cinema verdadeiramente de autor" (LEITE NETO, 2008, p. 4).

Em uma das sequências mais enigmáticas do longa, possivelmente orientada pela novela Dão-Lalalão, de João Guimarães Rosa, a câmera percorre um salão de festas. Um baile de carnaval anima o bordel. Os personagens dançam seminus pelos 
cômodos da casa. Homens e mulheres são iluminados por focos resplandecentes de luz metálica. Em pouco mais de oito minutos é possível observar a atmosfera crapulosa. Nesse tratamento visual neorrealista, a estética absorve máscaras, confetes e serpentinas, em um processo prateano de narrar. "Em Montes Claros, eu escrevia o roteiro mergulhado em seu universo erótico, enquanto olhava pela janela o jenipapeiro do sobrado", diz Prates (SERRA; IKEDA, 2013, p. 41). O diretor reconhece, ainda, a necessidade de homenagear o autor de Grande Sertão: Veredas.

A própria escolha da grafia do título - Cabaret, em francês, ao invés de Cabaré, em português - remete os espectadores a uma proposta alegórica da trama. É uma escolha não convencional, assim como a tipografia utilizada para apresentar o título do filme na abertura, dentro de uma janela que aponta para o céu e anuncia, simultaneamente, as dores e os prazeres da caatinga - outra marca de Rosa. Em Carlos Prates, nada é por acaso; tudo está enredado por um complexo jogo de bricolagem, territorialidade e memória. Essa teia de intertextualidades é vista por todo o longametragem, método permanente de tributos e de autocitações. Em alguns quadros, por exemplo, Cabaret Mineiro lembra Perdida (1975), segundo filme do diretor. É, assim, uma "presença recorrente de situações parecidas, recriadas de outras formas, em outras conjunturas narrativas", como notou Paiva Filho (2002, n.p.).

É certo que Prates se apropriou de elementos e de referências de outros filmes para construir Cabaret Mineiro, como Robinson Crusoé (1953), de Luis Buñuel, e Breathless (Acossado, 1960), de Jean-Luc Godard. Contudo, a estética é sertaneja. O som da viola, os folguedos estacionais, o bolo de fubá, a rapadura e o biscoito de goma entrelaçam as sequências por montanhas, cachoeiras e uma dose de contestação moral. Trata-se de um "mosaico de reminiscências mineiras" (MOURA, 1981, p. 25), reminiscências de um país profundo, fora dos lugares-comuns associados às Minas Gerais igrejas barrocas, o ouro, cidades coloniais etc. -, pouco conhecido no eixo Rio-São Paulo.

Como outros trabalhos de Carlos Prates - Crioulo Doido (1970) e Perdida (1975), por exemplo -, Cabaret Mineiro é um filme sobre marginalizados: prostitutas, malandros, boêmios, viajantes, homossexuais. O cenário é uma Minas Gerais específica, enquadrada na geografia cultural de João Guimarães Rosa - Januária, Pirapora, Salinas, Grão-Mogol, Janaúba, Mirabela, Bocaiúva. "Pela primeira vez a linguagem de Rosa, mais do que a de seus personagens, encontrou o seu par no cinema" (SIQUEIRA, 1985, p. 90). Seu elenco incorpora o macrocosmo edificado nas auras de Riobaldo e Diadorim, figuras de Grande Sertão: Veredas, esfinges das Alterosas. "Não há cronologia em suas representações" (RANGEL, 1997, p. 64) e "várias situações são desencadeadas, como nos sonhos, por pequenos elementos 
contidos em situações” (p. 78). Essa estratégia é vista em diferentes recursos de cena, como nos planos e nas iluminações. O próprio Prates reconhece o "cinema como fala literária envolvida por imagens" (SERRA; IKEDA, 2013, p. 44), em referência ao historiador e crítico Paulo Emílio Sales Gomes, cofundador da Cinemateca Brasileira.

Nas locações internas, a luz estourada toma conta das cenas e conduz o olhar rumo ao inusitado. Em planos médios, a história é filmada com iluminação intimista, quente e de alta carga de sensualidade. Durante o dia, o Sol é aproveitado sem exagero. Já no período da noite, uma atmosfera nebulosa assinala as cenas ou sequências, beirando uma melancolia semelhante à de Riobaldo e Diadorim: “Uma tristeza que até alegra” (ROSA, 2019, p. 26). Nas locações externas, é possível ver as planícies e vegetações rasteiras de Montes Claros, Grão-Mogol e Contria, locações de Cabaret Mineiro. É uma Minas rural, esquecida, tão incomum no cinema nacional, e cuja aridez é sentida nas retinas.

O trabalho de Prates é justamente este: fazer um cinema sertanejo, cravejado de insinuações literárias e de filmes da sua própria lavra. Compartilhar uma visão de mundo, uma “amálgama de referências históricas e afetivas" (MARINHO, 2018, p. 454). Tais insinuações se apresentam fragmentadas em um banquete de cenas que surgem na tela, mas que não necessariamente fariam falta se ali não estivessem. Um exemplo disso é a participação do grupo de marujada que desfila numa estrada de terra batida. É um ato contemplativo que sugere a ideia de infinito e remete ao desfecho de Grande Sertão: Veredas.

Cabaret Mineiro mergulha em uma cosmologia pessoal, isto é, a leitura de uma realidade influenciada pela formação afetiva do norte mineiro: juntas de boi, arroz com pequi, sol do meio-dia. No encontro fugaz de Paixão e Salinas, por exemplo, a tensão sexual está presente, mas é a paisagem bruta que passa pela janela do trem que marca o ritmo da sequência. "Natureza física”, como diz Prates (SERRA; IKEDA, 2013, p. 36), ao ser entrevistado para o catálogo da Mostra do Filme Livre.

O longa também apresenta um duelo antropofágico e bem-humorado entre Minas e o estrangeiro, representado por Thomas Caps - um estadunidense caricatural importado para o sertão. Nada mais oportuno que isso na obra de um diretor como Prates, que já defendeu a reserva de mercado não só para filmes nacionais, mas também para a narrativa literária mineira. "É possível identificar, no texto e no filme, tensões permanentes entre o local e o universal, variáveis igualmente presentes em Rosa”, explica a historiadora Maria Gabriela Marinho (2018, p. 455).

Na melhor piada da história, Paixão - fantasiado de Zorro - perde uma rodada de pôquer para Thomas Caps - vestido de indígena. Para reverter a maré baixa, 
o aventureiro inventa o CriCrí, combinação de cartas que, segundo ele, seria superior ao Royal Straight Flush. Entre as exclamações de surpresa dos outros jogadores, o estadunidense lança uma combinação ainda mais trocista para vencer. Resta ao aventureiro levar as mãos à cabeça e lamentar: "Salinas!". Nas cenas seguintes é Paixão que surge de índio nos braços de Caps, agora de Zorro. O choque entre o local e o universal surgirá noutras sequências - a cachaça versus o uísque ou o cigarro versus o charuto -, mas é no carteado que ele atingirá o seu momento mais simbólico, numa Las Vegas do semiárido mineiro.

\section{O reino da troça e do gozo}

Carlos Alberto Prates Correia nasceu em 1941, em Montes Claros, norte de Minas Gerais. Na época, os principais meios de informação ainda eram vendedores ambulantes e viajantes comerciais que singravam pelos rincões do estado. Ele passou a adolescência na terra natal, onde teve contato com manifestações populares da região. Fragmentos dessa convivência estão representados nos seus filmes, como o linguajar dos mercados, a dança dos catopês e o canto dos vaqueiros aboiando o gado. Essa paisagem poética recebe um tratamento erótico e político. Por vezes, o diretor consegue a façanha de combinar, num mesmo enredo, a pornochanchada da Boca do Lixo e a crítica social do Cinema Novo. Em ambos os casos, não há uma pretensão revolucionária. Reinam a troça e o gozo.

O cineasta se muda para Belo Horizonte na juventude - em data incerta, como boa parte da sua biografia - e começa a escrever críticas na Revista de Cinema e no Diário de Minas. Neste último, o ofício se estendeu por apenas seis meses. A vontade de dirigir os seus próprios filmes era incompatível com a de crítico de obras de outros. O primeiro trabalho no cinema surge ainda em 1965. Com 24 anos, o então sociólogo desempregado assumiu as funções de continuísta de O Padre e a Moça (35 mm, preto e branco, 90 minutos), segundo longa-metragem de Joaquim Pedro de Andrade (1932-1988). Adaptação de poema homônimo de Carlos Drummond de Andrade, o filme foi rodado em São Gonçalo do Rio das Pedras, distrito colonial do Serro. No mesmo set, Helena Ignez, que anos mais tarde se tornaria diva do cinema marginal, contracenou com não-atores, pessoas da comunidade onde o filme foi gravado. A experiência se tornou marca do cinema sertanejo. "Os não atores que trabalharam comigo eram bons porque, na verdade, eram atores", argumenta Carlos Prates (SERRA; IKEDA, 2013, p. 40).

Ainda em 1965, Carlos Prates participa da fundação do Centro Mineiro de Cinema Experimental, o Cemice. O núcleo reúne pessoas interessadas em explorar 
as linguagens da sétima arte e que passam as madrugadas na tradicional Cantina do Lucas falando de cinema. Dentre os fundadores do núcleo estavam Marcos Rocha, Tiago Veloso e Ricardo Noronha. O primeiro trabalho do Cemice é o curtametragem O Milagre de Lourdes (1965) (35 mm, preto e branco, 10 minutos), de Prates. Rodado em seis dias no bairro da Lagoinha, em Belo Horizonte, foi orçado em míseros quatro milhões de cruzeiros - algo em torno de 1.500 reais. A história conta as peripécias de um padre que foge de uma multidão enganada por ele numa rifa. $\mathrm{O}$ religioso acaba se escondendo num bordel, onde se apaixona por uma das concubinas. Não é por acaso que O Padre e a Moça e O Milagre de Lourdes têm enredos tão semelhantes. A princípio, a ideia era fazer quase uma releitura de Joaquim Pedro de Andrade, numa aproximação ao ambiente drummondiano.

Prates se muda para o Rio de Janeiro em 1966. Dois anos depois, dirige Guilherme, um dos episódios de Os Marginais ( 35 mm, preto e branco, 102 minutos). O longa de estreia viria em 1970. Rodado em Sabará, Crioulo Doido $(35 \mathrm{~mm}$, preto e branco, 80 minutos) é um dos primeiros filmes nacionais a ter um ator negro (Jorge Coutinho) como protagonista e em uma relação afetiva com uma atriz branca (Selma Caronezzi). O filme trabalha dois elementos cruciais: de um lado, o racismo estruturante numa pequena cidade, reflexo da sociedade brasileira; de outro, o status galgado pelo enriquecimento do personagem principal. "O ritmo lento e a estética depurada do filme ajudam a mostrar personagens como pálidas caricaturas de um mundo onde não há vontade própria”, explica o crítico Ruy Gardnier (2010, n.p.).

No drama do alfaiate Felisberto - negro, rico e rejeitado - ainda é possível entrever o lugar central que a paisagem sertaneja ocupará no trabalho do cineasta. Segundo Prates (SERRA; IKEDA, 2013, p. 36), "o que desejava era cruzar racismo com ascensão social, citando os Contos da Lua Vaga”, de Kenji Mizoguchi. "O que me interessava era contar os sonhos de poder daquele alfaiate e a busca da sua princesa Wasaka, que precederam a loucura que o dominou" (SERRA; IKEDA, 2013, p. 36).

Crioulo Doido é produzido com recursos do Pró-cinema, uma linha de crédito do Banco do Desenvolvimento de Minas Gerais (BDMG). Embora tivesse seguido o plano, com a conclusão dentro do prazo, o fracasso mercadológico não passou despercebido. As grandes salas não compraram a ideia de exibir um filme em preto e branco num momento de rápida popularização do cinema colorido. Houve problemas na distribuição e o longa-metragem ficou em cartaz por um dia.

O segundo longa de Prates ganhou moldura em 1975. Perdida $(35 \mathrm{~mm}$, colorido, 77 minutos) conta a história de Estela (interpretada por Maria Sílvia, atriz recorrente nos filmes do diretor), uma empregada doméstica maltratada pelo patrão 
que foge com um caminhoneiro e vai parar num prostíbulo. A obra teve problemas com a censura, foi picotada pelos generais e não teria concorrido em Gramado (RS) para evitar dissabores com o regime militar. Exibido, contudo, na Itália, foi considerado pela crítica romana como "o filme de maior peso, entre os inéditos, no XVII Festival de Cinema de Pesaro", garante o jornalista Claude Trionfera (1981, n.p.).

Já no Brasil, como aconteceu com outros filmes do cineasta, Perdida tampouco chegou ao grande público e ficou restrito às mostras independentes e cineclubes. Esse também foi o destino de Bem Atrás da Câmera (1978) 35 mm, colorido, 20 minutos), minidocumentário sobre o processo de produção e distribuição do cinema nacional. Se Bem Atrás da Câmera é dirigido a um público especializado, Perdida é, "seguramente, um dos mais importantes filmes de todo o cinema brasileiro", garante o crítico Ricardo Gomes Leite (1978, p. 26). Narra, com profundidade, o drama de uma doméstica convertida em mulher-objeto.

No início da década de 1980, Prates faz sua aproximação mais visceral ao universo de João Guimarães Rosa. É dessa fase a obra-prima Cabaret Mineiro (1980), com a mítica viagem de Paixão, Noites do Sertão (1983), que narra a história de uma mulher desquitada que vai morar numa fazenda, e Minas-Texas (1989), produzido por Prates sob o heterônimo de Charles Stone, um western à brasileira sobre uma donzela que foge com um peão de rodeio e enfrenta a quadrilha contratada pelo ex-noivo. Assim, o diretor aprofunda a adaptação da literatura para o cinema. Se a aproximação é evidente em Noites do Sertão ou Cabaret Mineiro, a inspiração para Minas-Texas também saiu das páginas de Buriti, de Guimarães Rosa, em Corpo de Baile. A donzela e o peão do longa são, na verdade, Totonho e Dô-Nhãninha da novela. Mudam-se os personagens, mas o enredo é o mesmo.

A riqueza de Prates está em propor um projeto estético único, pessoal e complexo. Em entrelaçar a aridez e o erotismo do sertão, em glorificar antiheróis, prostitutas, bêbados, viajantes, boêmios e peões. Nas palavras da crítica Andrea Ormond (2008, n.p.), Prates mostra "que a importância de se olhar o povo é descobri-lo em suas falhas e insensatez". O diretor amplifica a caatinga, a viola, a cachaça, a pimenta, a rapadura e a carne de sol. Uma estética do deleite plotada na paisagem roseana.

Em 16 de março de 1990, o então presidente da República Fernando Collor de Mello encerra a Empresa Brasileira de Filmes (Embrafilme), estatal responsável por fomentar a produção e a distribuição do cinema nacional. A sétima arte brasileira entra em uma profunda crise (BERNARDET, 1990). Repentinamente, Prates interrompe a sua maquinaria. Reservado e avesso a entrevistas, pouco se conhece da 
vida e obra do diretor nesse período. Aliás, com poucas exceções, investigar o cinema mineiro é como vasculhar um sítio arqueológico. As peças nem sempre se encaixam e, muitas vezes, indicam informações não verificáveis.

A volta de Prates ao cinema autoral só aconteceria quase 20 anos depois de Minas-Texas. Em 2007, lançou Castelar e Nelson Dantas no País dos Generais ( $35 \mathrm{~mm}$, colorido e preto e branco, 73 minutos). O filme combina elementos ficcionais e documentais para apresentar a história do cinema mineiro na Ditadura Militar (1964-1985). Entre os diretores escolhidos estão Humberto Mauro, Joaquim Pedro de Andrade, Alberto Graça, Schubert Magalhães e Andrea Tonacci. O "semidocumentário" é escolhido como melhor filme do $35^{\circ}$ Festival de Gramado, mas Prates não comparece ao evento. Explicação? Nenhuma.

Em entrevista para o forumdoc.bh (MESQUITA; SABINO; FONSECA, 2008, p. 146), o cineasta foi questionado: "Por que, cada vez mais, cria filmes sobre outros filmes?", em referência ao Castelar e Nelson Dantas no País dos Generais. A resposta veio apimentada, como a comida de Montes Claros: "Porque é esse o meu desejo, a minha possibilidade. E por que não haveria de criar? Você é de alguma polícia estética? Eu costumo enfrentar patrulhas mercadológicas, agora tem essa outra?" (MESQUITA; SABINO; FONSECA, 2008, p. 146).

\section{O som metálico das Gerais}

A câmera segue Salinas, de vestido vermelho e cigarrilha na mão, até a entrada do vagão-restaurante. Ela observa Paixão, que, sozinho, joga cartas. A imagem corta para a janela. Na paisagem, a caatinga. Em novo corte para o interior do trem, Salinas pergunta: "Posso acompanhá-lo?". O aventureiro observa a mulher, em silêncio. Ela continua: "Vou sentar assim mesmo". Ele responde, teatralmente: "Vendo os seus lábios encarnados, seu corpo ardente de desejo, deixo de supor que as migalhas de afeto do maravilhoso âmago possam se transformar em pequis inatingíveis". A câmera foca os movimentos sob a mesa. Salinas descruza as pernas e esfrega as coxas. É sensual, ardentemente sensual. A câmera focaliza o rosto dela, que diz: "Os seus olhos já bastavam tanto e agora você fala essas coisas. Eu morro". Eles se beijam aos sons da locomotiva.

Vencedor de sete categorias no $9^{\circ}$ Festival de Gramado, como as de Melhor Filme, Diretor e Trilha Sonora, Cabaret Mineiro é marcado por uma oralidade muito específica. Lapidada no dia a dia, enquanto o filme era rodado, cria a atmosfera fantasiosa e regional da história - outra marca de João Guimarães Rosa. O encontro fugaz de Paixão e Salinas, por exemplo, revela a força mágica que 
as palavras ganham ao serem enunciadas. Recurso similar também é ouvido nos diálogos de Noites do Sertão (1984) e Minas-Texas (1989).

Essa dicção, com um sentido de musicalidade na voz, surge sempre da indecisão entre natural versus teatral, de maneira intimista e recitativa. Sem eleger o seu platô definitivo, a fala é uma máquina de aproximação e distanciamento. Ela edifica tensões na entonação dos discursos e das cantorias populares e permite que cada personagem esteja na iminência do rompante poético. Um sussurro prestes a explodir. Assim, "o diretor coloca seus personagens numa camisa de força, um universo fechado caracterizado por várias formas de coerção moral, psicológica, social, econômica, geográfica e mítica” (SIQUEIRA, 2002, p. 1).

Em Gramado, Carlos Prates provocou a mesma estranheza que Jean-Luc Godard causara, nas décadas de 1960 e 1970, em Paris. Nos bastidores do festival, corriam boatos de que Cabaret Mineiro era um filme fragmentário, recortes de imagens avulsas. De fato, a escolha do filme pela comissão julgadora - Ruy Guerra, Dina Sfat e Ronaldo Lima Lins - gerava certo desconforto. Todas as apostas indicavam O Homem Que Virou Suco (1981), de João Batista de Andrade, e Eu Te Amo (1981), de Arnaldo Jabor, como os prováveis vencedores. Afinal, eram tramas mais lineares e com um certo apelo mercadológico. Dias depois, o diretor Roberto Moura rebate os críticos da fragmentação em O Pasquim: "Coitados, vão ter que ver de novo. Estamos diante da obra mais harmoniosa que o cinema brasileiro nos ofereceu nos últimos anos" (MOURA, 1981, p. 25).

Os enquadramentos de Prates fascinam pela ausência de pirotecnias e pelo diálogo que estabelece com a alma sertaneja, em um eterno retorno à rua de baixo. Por remar contra as tendências, a maioria dos seus filmes mal conseguiu chegar às salas de cinema - foram sucesso de crítica e fracasso de público. Na contramão do mercado, os filmes arrebataram dezenas de prêmios nacionais e estrangeiros, mas também lançaram o diretor à margem da grande indústria cinematográfica. É difícil ter acesso ao trabalho completo de Prates, mesmo em locadoras especializadas e plataformas de streaming. Com "lugar de destaque no cinema brasileiro", "falta só a historiografia traduzir essa envergadura em mais estudos", acredita o pesquisador Mateus Araújo (HISTÓRIA..., 2020).

$\mathrm{Na}$ mesma linha, a música exerce papel fundamental na obra de Prates. Mais que mero acompanhamento de imagens, monólogos ou diálogos, ela caracteriza o meio social da trama. Desde o longa-metragem Perdida (1975), Prates estabeleceu uma parceria bem-sucedida com o músico e compositor Tavinho Moura, que assina a trilha de Cabaret Mineiro. A história de Paixão e Salinas ainda 
se chamava O Aventureiro do São Francisco quando a enchente de 1979, no Velho Chico, inviabilizou o roteiro original. Inicialmente, o filme narraria a viagem de barco de um jogador de cartas que, pelos caminhos liquefeitos do rio São Francisco, faz amigos, se apaixona, visita lugarejos remotos e se envolve com prostitutas. Já para o novo argumento, Prates pede a Tavinho Moura para musicar Cabaré Mineiro, de Carlos Drummond de Andrade:

A dançarina espanhola de Montes Claros
dança e redança na sala mestiça
Cem olhos morenos estão despindo
seu corpo gordo picado de mosquito.
Tem um sinal de bala na coxa direita,
o riso postiço de um dente de ouro,
mas é linda, linda, gorda e satisfeita.
Como rebola as nádegas amarelas!
Cem olhos brasileiros estão seguindo
o balanço doce e mole de suas tetas.
(ANDRADE, 2013, p. 64)

No local da filmagem e com apenas seis sequências escritas, Cabaret Mineiro foi roteirizado e rodado simultaneamente. As canções - a maioria adaptações de temas folclóricos do norte de Minas - eram executadas na própria locação, sem playback e retake. Esse é o caso das cenas em que Paixão e Maruja (Eliene Narducci) fazem dueto de um motivo popular, nas ruínas de um sobrado de pedra. Tavinho Moura (violão) e Sílvia Beraudisam (flauta) tocam fora do quadro. Paixão canta a primeira estrofe. Maruja, a segunda. Os dois entoam o versinho como refrão: "Nem dormir tenho dormido / Deito na cama e não durmo / Meu semblante é teu sentido”.

Com a sequência finalizada, Tavinho Moura (2004, n.p.) se lembra de ouvir a gravação: "Estava boa pra cacete, tinha um grilo ali, uma coisa aqui e tal, mas bonito. E isso é uma coisa difícil de fazer porque não é playback”. O músico também contracena no longa. Ele é Ernesto, jovem revolucionário, de bigode e boina verde com uma estrela vermelha, numa alusão às guerrilhas latino-americanas da época. Tem, contudo, só uma fala: "Perdi-a porque acredito na utopia", no contexto do fracasso das suas investidas amorosas em Avana - dançarina espanhola de um bordel de Montes Claros. Mais uma vez, a voz plaina na hesitação entre o natural e o teatral.

Em Cabaret Mineiro, as músicas descrevem a essência das cenas, captando a aura da locação. Por vezes, o mecanismo sonoro é utilizado para transmitir os sentimentos e o universo imaterial do filme, indo do mais completo humor aos momentos contemplativos. Um exemplo desse projeto é visto na sequência em que 
Paixão canta Suíte do Quelemeu, um motivo popular adaptado por Tavinho Moura, para a jovem Evangelina (interpretada por Dora Pellegrino, então com 20 anos incompletos):

Vamos dançar tudo nu, tudo nu
Tudo com o dedo no cu, menos eu
Tudo com a bunda de fora, é agora
Você disse que dava e não deu
Espora no pé tá tinindo, tá tinindo
Pica no cu tá sumindo, tá sumindo
Larga teu marido, mulher
E vem foder mais eu
Teu marido é bom, mulher
Mas não fode como eu
A foda boa é de madrugada
De manhã cedo não vale nada
A pica tá dura, que tá danada
Ela entra enxuta, ela sai molhada etc.
(MOURA, 1981, faixa 9)

Num quarto de pensão, a câmera foca Evangelina, entediada, que masca chicletes. A imagem corta para o aventureiro Paixão, que olha atentamente a garota. A câmera volta para Evangelina, que, enquadrada entre os ombros e o abdômen, acaricia o seio sob a camisa social branca. Ele canta. Ela escuta. Novo corte seco para Paixão. Enquadrado do abdômen aos joelhos, agora com as pernas trêmulas de desejo, o aventureiro abre o zíper das suas calças de linho. A câmera vai abruptamente para a fachada de um armazém de secos e molhados. Esconde o que todos imaginam, embalada por Lady Laura, de Roberto Carlos: “Tenho às vezes vontade de ser / Novamente um menino / E na hora do meu desespero / Gritar por você / Te pedir que me abrace / E me leve de volta pra casa”. Esse é o deboche sertanejo, ouvido em outros motivos, como Maria Manteiga e Bunda Virada, em contraste com faixas contemplativas, como A rua de baixo e Meu semblante é teu sentido.

As músicas de Cabaret Mineiro foram lançadas em Long Play (LP), pela Embrafilme e, depois, pelos estúdios Odeon, logo após o prêmio de Melhor Trilha Sonora no Festival de Gramado. Mas o disco, com 19 faixas, teve problemas com a censura e chegou às lojas em embalagem lacrada e com tarja preta na capa: "Impróprio para menores de 18 anos | Execução pública proibida | Músicas pornográficas". É o som metálico das Gerais fustigado pelos militares.

Na época, críticos rebateram as acusações de que o filme teria muitos palavrões e que seria demasiado libidinoso para o Brasil dos anos 1980. No entanto, a própria RCA, gravadora de Tavinho, já havia mostrado desinteresse em fazer a prensagem comercial da trilha. Na verdade, os personagens de Carlos Prates são amavelmente 
abrutalhados. Quase sempre homens de meia-idade, muito longe do padrão de beleza, apostam na pirraça e na velhacaria como artefatos de encantamento. Já as mulheres, sempre jovens, belas e ícones do mise-en-scène - Maria Sílvia, Débora Bloch, Tânia Alves, Dora Pellegrino -, assumem papéis incendiários da moral judaico-cristã. Porém, existe uma certa inocência no tom como até as palavras mais provocantes são pronunciadas, e as músicas acompanham esse dizer. Não ofendem, tampouco buscam lacerar os mais puros. As maiores grosserias soam como misteriosas canções de ninar.

Se no Brasil o LP teve problemas com o regime militar, na França provocou a maior euforia. É Tavinho que narra a história: "Quando o filme passou em Cannes, na mostra paralela, levaram o disco. Diz o Nelson Horneff que foi uma verdadeira briga pra comprar o disco depois da sessão. Eles só tinham levado cem Long Plays" (MOURA, 2004, n.p.). Com participação especial do Uakti e de Flávio Venturini, o álbum tem ainda dois sambas de Noel: Nunca... Jamais e Pra Esquecer.

Depois de Cannes, Cabaret Mineiro passou por diversos países, sempre dentro de festivais e de mostras, como Alemanha, Canadá, Estados Unidos, Argentina e Itália, mas nunca nas grandes salas. Embora críticos como Jean-Claude Bernardet acreditassem que o filme de Prates fosse "um dos grandes momentos do cinema dos últimos trinta anos" (BERNARDET, 2013, n.p.), do mesmo calibre de O Bandido da Luz Vermelha (1968), de Rogério Sganzerla, e de Terra em Transe (1967), de Glauber Rocha, o longa mineiro não era comercial nem comercializável. Ainda que perfilado na lista dos cem melhores filmes nacionais de todos os tempos (DIB, 2015), é um ilustre desconhecido. Está na filmoteca dos cinéfilos, mas não no imaginário popular.

Carlos Prates segue arredio. Como um bom sertanejo, não dá entrevistas, não tem perfil em redes sociais, não vai a programas de televisão. Não reúne consenso nem dentro nem fora da indústria. É um anônimo entre anônimos. Com uma filmografia relativamente pequena - seis longas, três curtas -, o seu lugar é atrás das câmeras, no meio do redemoinho místico do norte de Minas. Nele, o filme é obra de comunhão e espanto. Surpreende, em larga medida, porque serve para iluminar o belo escondido pelas coisas miúdas. Um belo talhado pela poeira das Gerais, das serras mineiras, ourives do tempo. É uma filmografia que edifica pontes entre o sarcasmo e o cândido. Traça linhas de aproximação entre o cinema e a literatura. Nesse fazer movediço, Prates cruza a velha rua de baixo com as ruas de todo o mundo. É o seu próprio anti-herói numa eterna viagem de trem a Montes Claros. Paixão e Salinas. 


\section{Referências}

ANDRADE, C. D. Alguma poesia. São Paulo: Companhia das Letras, 2013.

BERNARDET, J. “A crise do cinema brasileiro e o plano Collor”. Folha de S.Paulo, São Paulo, ano 70, n. 22.533, p. 3 , 23 jun. 1990. Disponível em: https://bit.ly/3nrllEP. Acesso em: 13 set. 2021.

BERNARDET, J. Uma atitude lúdica. Cinema de Prazer de Carlos Alberto Prates Correia, [S. l.], c2013. Disponível em: https://bit.ly/3e8iz2r. Acesso em: 20 dez. 2020.

DIB, A. Abraccine organiza ranking dos 100 melhores filmes brasileiros. Abraccine, [s. l.], 27 nov. 2015. Disponível em: https://bit.ly/3ed7Sf7. Acesso em: 18 dez. 2020.

GARDNIER, R. “Crioulo Doido (1970)”. Contracampo, São Paulo, n. 30, 2010.

HISTÓRIA permanente do cinema | Cabaret Mineiro de Carlos Alberto Prates Correia. [S. l.: s. n.], 2020. 1 vídeo (1h 32min 05s). Publicado pelo canal Palácio das Artes - Fundação Clóvis Salgado. Disponível em: https://bit.ly/3zcf0ze. Acesso em: 27 abr. 2021.

IKEDA, M. "Para além da mineirice: a natureza no cinema de Carlos Alberto Prates Correia”. In: Catálogo da Mostra do Filme Livre. Rio de Janeiro: Centro Cultural Banco do Brasil; Ministério da Cultura, 2013. p. 26.

LEITE NETO, A. "O que fazer com Prates Correia, 1986”. In: CD Livreto de Carlos Prates. São Paulo: Editora do Autor, 2008. p. 1-4.

LEITE, R. G. "Perdida - dossiê crítico". Filme Cultura, Rio de Janeiro, n. 29, p. 25-33, 1978.

MARINHO, M. G. S. M. C. “Cabaret mineiro: lirismo e transgressão no ocaso da ditadura”. In: MAIA, G.; ZAVALA, L. (org.). Cinema musical na América Latina: aproximações contemporâneas. Salvador: EDUFBA, 2018. p. 453-467.

MESQUITA, C.; SABINO, F.; FONSECA, J. "Entrevista Carlos Prates". Forumdoc.bh $-12^{\circ}$ Festival do Filme Documentário e Etnográfico, Belo Horizonte, 2008. p. $145-150$.

MOURA, R. “Andar aí no seu gramado”. O Pasquim, Rio de Janeiro, n. 615, p. 25, 1981.

MOURA, T. História de Otávio Augusto Pinto de Moura (Tavinho Moura). Museu da Pessoa, [S. l.], 12 dez. 2004. Disponível em: https://bit.ly/3uaSPrM. Acesso em: 20 dez. 2020. 
ORMOND, A. Perdida. Blog Estranho Encontro, [S. l.], 7 set. 2008. Disponível em: https://bit.ly/2Siu4fb. Acesso em: 9 jan. 2021.

PAIVA FILHO, A. "A marujada surreal, safada e alterosa do capitão Prates". Sombras Elétricas, Niterói, n. 1, 2003. Disponível em: https://bit.ly/3tBxlGl. Acesso em: 9 jan. 2021.

RANGEL, M. "A rua de baixo: análise do filme Cabaret Mineiro, de Carlos Alberto Prates Correia”. Revista Balalaica, São Paulo, n. 1, p. 64-78, 1997.

ROSA, J. G. Grande Sertão: Veredas. São Paulo: Companhia das Letras, 2019.

SERRA, C.; IKEDA, M. "Entrevista". In: Catálogo da Mostra do Filme Livre. Rio de Janeiro: Centro Cultural Banco do Brasil, 2013. p. 35-47.

SIQUEIRA, S. "Cabaret Mineiro (review)". Framework: The Journal of Cinema and Media, New York, n. 28, 1985.

SIQUEIRA, S. "O diabo na rua, no meio do redemoinho..." In: Catálogo da Retrospectiva Prates Correia. São Paulo: Centro Cultural São Paulo, 2002. p. 1.

TRIONFERA, C. "Uma jóia brasileira com acentos trágicos e ecos emblemáticos". Cinema de Prazer de Carlos Alberto Prates Correia, [s. l.], c2013. Disponível em: https://bit.ly/2QMAxyn. Acesso em: 9 jan. 2021.

\section{Referências audiovisuais}

CABARET Mineiro. Carlos Prates, Brasil, 1980.

CRIOULO Doido. Carlos Prates, Brasil, 1970.

MINAS-TEXAS. Carlos Prates, Brasil, 1989.

PERDIDA. Carlos Prates, Brasil, 1975.

CABARET Mineiro. [Compositor]: Tavinho Moura. São Paulo: EMI-Odeon, 1981. $1 \mathrm{CD}(31 \mathrm{~min})$. 